\section{The Last Rain Forests}

Edited by Mark Collins

Mitchell Beazley, London, 1990, 200pp., HB £17.99

Rain forest conservation issues are complex and difficult to comprehend in their entirety. Some concerns are passionately advocated, while others are often skated over, further distorting, complicating and ultimately obscuring the problems while deforestation continues apace. The Last Rain Forests provides an antidote; this is no polemic but a measured, comprehensive and authoritative overview. It is, furthermore, interestingly written and extremely informative, through its lavish illustration no less than its text.

The way that the different aspects of rain forest conservation are teased apart, clearly presented, and fitted back into the whole is the sign of an editor who is a master of his subject. And this is only half the book; the other half consists of large-scale maps of the world's rain-forest regions and additional information about them. Anyone familiar with the situation on the ground in any given region may be able to find points of detail to quibble about-forest patches missing or degraded areas included-but this is hardly important. These are the most accurate large-scale maps of the world's rain forests that are available and their production is a great achievement.

The Last Rain Forests is a valuable publication, the best general book on the subject that is available.

\section{Dolphins: Their Life and Survival \\ Michael Donoghue and Annie Wheeler \\ Blandford, London, 1990 (in}

association with David

Bateman Ltd, Auckland), 119pp., HB $£ 14.95$

Public interest in whales and dolphins has never been greater, yet how many people have ever even seen one? The same goes for otters. There is also a lot of interest in tropical forests, yet relatively few people have ever been to one. It almost seems as though people feel more concerned about the conservation of species, the less their own direct personal experience! This anomaly is fostered and perhaps even brought about by a plethora of books and TV programmes, each of which seems to stimulate production of still more on similar subjects. So, do we really need yet another book on cetaceans and if so, what has this one got to commend it?

Well, first it is about dolphins rather than the big whales that dominated cetacean books a decade or more ago. This reflects a welcome trend towards studying cetaceans for their own sake and as highly intelligent creatures, rather than just killing them for dogfood. Second, the smaller species have often been overlooked because of the attention accorded to their leviathan cousins. They have also been overlooked because they live at sea, making them more difficult to investigate than land animals. Yet many of the dolphins are endangered and pose important conservation problems every bit as serious as for terrestrial species.

The main part of this book deals with these dolphin-related conservation issues, including the river dolphins, not just the marine species. There are chapters on the dangers of giant driftnets $(50,000 \mathrm{~km}$ of which are set every night in the fishing season in the North
Pacific), threats from tuna (and other) fishermen, insidious chemical dangers and the issues posed by captive dolphins and their study and use by the military. The first part of the book is a 'who's who' guide to the various threatened species (stretching 'dolphin' a bit to include narwhal, beluga and killer whale!) and their conservation status. There is also a review of the basic biology of these animals and the often moving relationships of individuals with humans. The final section is about legal protection, and conservation efforts, with suggestions about ways in which individuals can help.

The book is detailed, wellwritten and much enhanced by little marginal notes, which amplify background details (e.g. information about diets or diving physiology). There are substantial text boxes, which contain relevant background stories (e.g. telling of the conflicts that have arisen over the taking of dolphins into captivity). There are also many excellent colour plates.

Altogether this is a very worthwhile and useful book. It gives details and brings up to date many of the scattered stories, often mentioned frustratingly 'Briefly' in Oryx. There is certainly room for this book among all the others, and at its price is much better value than some.

Pat Morris.

\section{United Nations List of National Parks and Protected Areas \\ IUCN, Gland, Switzerland and Cambridge, UK, 1990, 284 pp., SB $£ 12.50 / \$ U S 25$}

This list of national parks and protected areas has been extensively revised and updated 